\title{
ESTRUTURAS ELÁSTICAS E FADIGA MUSCULAR
}

\section{MS. GLÁUCIA ANDREZA KRONBAUER}

Mestrado em Ciências do Movimento Humano pela Universidade Federal do Rio Grande do Sul (ESEF/UFRGS), Professora do Instituto Federal de Ciência e Tecnologia do Paraná (IFPR) e da Universidade Estadual do Centro-Oeste, Paraná (UNICENTRO) (Irati - Paraná - Brasil)

E-mail: glaucia.a.k@hotmail.com

\section{DR. FLÁVIO ANTÔNIO DE SOUZA CASTRO}

Doutorado em Ciências do Movimento Humano pela Universidade Federal do Rio Grande do Sul (ESEF/UFRGS), Professor da Escola de Educação Física Universidade Federal do Rio Grande do Sul e Coordenador do Programa de Pós-Graduação em Ciências do Movimento Humano (ESEF/UFRGS)

(Porto Alegre - Rio Grande do Sul - Brasil)

E-mail: souza.castro@ufrgs.br

\section{RESUMO}

A fadiga muscular pode ser definida pela incapacidade de manter certa tarefa ao longo do tempo; os mecanismos neuromusculares e metabólicos envolvidos na contração muscular estão diretamente associados a esse fenômeno. Este estudo bibliográfico busca descrever as alterações nos elementos contráteis e elásticos envolvidos na contração muscular e sua relação com o desempenho na locomoção. As estruturas contráteis são aquelas que desenvolvem força ativa com gasto de energia metabólica - mecanismo de pontes cruzadas; as elásticas são aquelas que oferecem resistência mecânica ao alongamento sem custo energético - força passiva - e conservam energia elástica para uma nova contração. Após a análise de ambas, é possível afirmar que a fadiga muscular está associada à função das estruturas contráteis e elásticas.

PALAVRAS-CHAVE: Elementos contráteis; elementos elásticos; fadiga muscular; locomoção. 
A fadiga muscular é um fenômeno que envolve mecanismos complexos em diversos sistemas do corpo humano. Costuma-se definir fadiga pela incapacidade de manter certa tarefa ao longo do tempo. Duas propostas para explicar a fadiga são, em geral, apresentadas. A primeira, e mais antiga delas, está baseada no colapso total, ou seja, devido à depleção de substratos, acúmulo de metabólitos, falhas na ativação, alteração do fluxo de cálcio e dificuldade de estabelecimento de pontes cruzadas entre actina e miosina, o músculo se torna incapaz de produzir força (AMENT; VERKERKE, 2009).

Uma segunda proposta, que surgiu nos últimos anos, se baseia na prevenção organizada por um comando central (central governor). Segundo os pesquisadores dessa linha, a tarefa seria interrompida antes, justamente para prevenir o colapso total (BARON et al., 2007; AMENT; VERKERKE, 2009). Estudos têm demonstrado que músculos fadigados, a princípio, mantém sua capacidade de produção de força quando submetidos, por exemplo, à estimulação elétrica (BARON et al., 2007; TAYLOR; GANDEVIA, 2008). Esses resultados sugerem que a interrupção de uma tarefa ou gesto motor não está restrita aos fenômenos locais que acontecem no músculo.

Deste modo, a origem da fadiga muscular está ainda em discussão. O que se pode observar, no entanto, é a modificação do desempenho em resposta à fadiga. Nesse sentido, este estudo bibliográfico busca descrever as alterações nos elementos contráteis e elásticos envolvidos nos mecanismos de contração muscular em resposta ao exercício extenuante e sua relação com o desempenho na locomoção.

\section{MECANISMOS CONTRÁTEIS E NÃO-CONTRÁTEIS DE PRODUÇÃO DE FORÇA}

A célula muscular possui uma capacidade única entre os tecidos biológicos: responde a estímulos elétricos, se contrai e gera força. Segundo a teoria das pontes cruzadas descrita por Andrew Huxley e Hugh Huxley (HUXLEY; HANSON, 1954; HUXLEY; NIEDERGERKE, 1954), a contração muscular acontece por meio do mecanismo de filamentos deslizantes. O sarcômero, estrutura funcional que se encontra ao longo de toda a célula muscular, é constituído por filamentos de actina e miosina, proteínas com forte atração entre si. Ao longo da contração, os filamentos de actina e miosina estabelecem pontes cruzadas por ciclos de acoplamento-desacoplamento causando encurtamento muscular (HUXLEY, 1957). Esses ciclos acoplamento-desacoplamento acontecem por meio da quebra de moléculas de ATP (energia) em ADP + Pi, ou seja, dependem da energia metabólica disponível no músculo. 
Na teoria das "pontes cruzadas", uma característica funcional importante é a dependência do comprimento da fibra muscular para a geração de força. Descreve uma fase ascendente, na qual a força e o comprimento de sarcômero aumentam simultaneamente, uma fase de platô e uma fase descendente, com aumentos extremos de comprimento e redução da força durante a contração devido ao número de pontes cruzadas estabelecidas em cada comprimento (GORDON; HUXLEY; JULIAN, 1966). Em músculos ou fascículos essa relação é um pouco diferente, com um comportamento ascendente-descendente não linear, mas curvilíneo (HERZOG; TER KEURS, 1988), que representa a soma da ação de vários sarcômeros.

Durante a fase descendente da curva força $\times$ comprimento muscular, com aumentos extremos de comprimento, entretanto, existe a soma de uma força extra que se deve aos componentes passivos, ou seja, aqueles componentes capazes de oferecer resistência mecânica ao alongamento sem gasto de energia metabólica (NATORI, 1954; GORDON, HUXLEY; JULIAN, 1966; WOITTIEZ et al., 1984). Sendo assim, a força muscular total é composta por força ativa e força passiva, conforme mostra a Figura I apresentada por Herzog (2009) e adaptada do esquema original proposto por Gordon; Huxley e Julian. (1966).

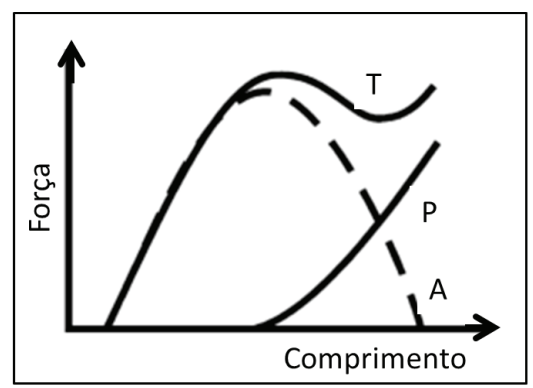

Figura I - Relação força x comprimento de um músculo isolado. t) força total; a) força ativa; p) força passiva. Fonte: Adaptado de Herzog, 2009.

Assim, além das estruturas contráteis (as pontes cruzadas de actina e miosina), o músculo esquelético possui também estruturas não contráteis responsáveis pela resistência passiva, ou seja, resistência oferecida sem gasto de energia. Segundo Wottiez et al. (1984), a força passiva de uma fibra muscular em seu comprimento ótimo de produção de força é de aproximadamente 6,5\% da força ativa máxima em um abalo - entende-se abalo como a resposta contrátil a um único potencial de ação. Já em uma fibra alongada a 130\% do seu comprimento ótimo, a força 
passiva é de aproximadamente $87 \%$ da força ativa máxima, sendo o aumento de força exponencial ao alongamento.

Os componentes de produção de força podem então ser definidos como: a) componentes ativos, relacionados principalmente com a parcela de sobreposição de miosina e actina (HUXLEY, 1957; GORDON; HUXLEY; JULIAN; 1966; MACINTOSH; MACNAUGHTON, 2005); e b) estruturas passivas, como a membrana celular, tecido conjuntivo intersticial e componentes do citoesqueleto (GORDON, 1966; ALEXANDER, 2002; HERZOG; LEONARD, 2002; MACINTOSH; MACNAUGHTON, 2005; PINNIGER, RANATUNGA, OFFER , 2006).

O tecido conjuntivo que envolve as fibras, os fascículos e o músculo todo é composto por teias de fibras de colágeno que formam endomísio, perimísio e epimísio, respectivamente. Análises microscópicas têm demonstrado que essas fibras, principalmente no perimísio, mudam sua organização durante alongamentos, desfazendo sua formação ondulada e se organizando em paralelo. Esse processo de mudança seria responsável por oferecer resistência ao alongamento muscular (BORG; CAULFIELD, 1980; WILLIAMS; GOLSPINK, 1984; PURSLOW, 1989). Considerando essa especial propriedade do perimísio, está sendo estudada hipótese de que o tecido conectivo possa se contrair ativamente, aumentando a rigidez muscular durante alongamento (SCHLEIP, et al., 2006).

Citam-se ainda a força passiva vinda de filamentos intermediários, cadeias de proteínas localizadas nos discos Z e na periferia de miofibrilas, paralelas e perpendiculares às fibras musculares. Têm a função de manter a estrutura das miofibrilas e evitar mudanças muito grandes no comprimento de sarcômeros vizinhos, mantendo certa homogeneidade e prevenindo lesões (WATERMAN-STORER, 1991; SANDERCOCK, 2000).

Outra importante cadeia proteica responsável pela força passiva é a titina. Conhecida também como a molécula gigante do sarcômero, apresenta em média I $\mu \mathrm{m}$ de comprimento e, além da função estrutural nos discos $Z$ e na ligação entre a miosina ao disco Z, está envolvida também em mecanismos de regulação das pontes cruzadas, auxiliando a manter a conformação da miosina durante a contração (MINAJEVA, et al., 200 I; TSKHOVREBOVA; TRINICK, 2003). Quando exposta ao estresse mecânico atua como sinalizadora e reguladora da expressão gênica para a síntese de proteínas (GRANZIER; LABEIT, 2006). Possui sequências de imunoglobulinas e uma estrutura PEVK, composta por prolina $(P)$, glutamato $(E)$, valina $(V)$ e lisina $(K)$. A sua região localizada na banda I é funcionalmente extensível, a região localizada na Banda A é rígida devido à forte ligação com a miosina (LINKE et al., 1998).

A titina possui ainda forte relação com o cálcio intramuscular e é capaz de aumentar sua rigidez durante o alongamento ativo do músculo, ou seja, em contração 
excêntrica. Joumaa et al. (2007), ao testarem miofibrilas isoladas (sarcômeros em série), observaram aumento da força passiva depois de alongamento ativo. Concluíram que a titina, como estrutura passiva do sarcômero, deve ser responsável pelo aumento de força; e que o aumento só acontece em alongamento ativo, ou seja, parece haver um aumento na rigidez da titina induzido pela ativação muscular (JOUMAA, et al., 2007).

\section{ESTRUTURAS PASSIVAS E ENERGIA ELÁSTICA}

As estruturas passivas do sistema muscular são capazes de oferecer resistência mecânica durante o alongamento. A tensão passiva máxima é produzida no maior comprimento muscular, a partir do qual, caso o alongamento continue, as fibras começam a romper e a força passiva diminui (GAJDOSIK, 200 I). Normalmente esse comprimento pré-ruptura está relacionado à máxima amplitude de movimento articular.

Além disso, têm a propriedade de conservar energia mecânica elástica durante o alongamento. A tensão gerada pela energia acumulada é responsável pela retração espontânea do músculo para o comprimento de repouso pela liberação da energia elástica acumulada (ALEXANDER, 2002; GOSSELIN, 1998). Por isso o termo "propriedades elásticas" tem sido utilizado no estudo da função muscular (MACINTOSH; MACNAUGHTON, 2005; SANDERCOCK, 2000).

Mais especificamente, segundo Mutungi (2003), as estruturas passivas apresentam um comportamento visco-elástico. Quando o alongamento ativo acontece, a tensão pode aumentar proporcional ao aumento da velocidade (viscoso), pode alcançar um platô (visco-elástico) ou pode ser independente da velocidade (elástico). Em situações de velocidades baixas de alongamento ativo predomina a tensão visco-elástica e elástica.

A titina, por exemplo, tem sido descrita como uma mola-ativa capaz de armazenar energia elástica durante alongamento (HERZOG; LEONARD, 2002). Com pequenas deformações a titina se comporta como um elástico perfeito retornando a seu estado inicial; já em deformações próximas a 40\% do comprimento inicial, existe uma deformação plástica (MARUYAMA, et al., 1977). Acredita-se também que suas características de comprimento e rigidez se modificam quando, por exemplo, o seu ambiente bioquímico altera - aumento da $\left[\mathrm{Ca}^{2+}\right]$ durante a ativação muscular; diminuição da possibilidade de quebra de ligações moleculares terciárias, que mantém a proteína em sua forma espiralada, ou seja, sua estrutura conformacional de equilíbrio. Esta capacidade de armazenar energia acontece apenas durante o alongamento ativo do músculo, ou seja, não se pode afirmar que a titina isoladamente influencia na força total do músculo (LEE; JOUMAA; HERZOG, 
2007). Parece inclusive que a rigidez da titina aumenta durante o alongamento ativo, o que pode estar relacionado realmente às concentrações sarcoplasmáticas de cálcio durante a contração, ou seja, a tensão produzida pela titina seria cálcio-dependente (LABEIT, 2003).

Em termos práticos, essa capacidade de armazenar e liberar energia elástica significa desempenho realizado sem a necessidade de energia metabólica. Ou seja, enquanto em contrações puramente concêntricas ou isométricas o trabalho desenvolvido pelo músculo se deve exclusivamente às pontes cruzadas estabelecidas - sendo estas dependentes de ATP (energia metabólica) - durante contrações excêntricas ou ciclos alongamento-encurtamento soma-se a energia mecânica elástica e o mesmo trabalho pode ser realizado com menor custo metabólico (ABBOT; AUBERT, 1952; EDMAN; ELZINGA; NOBLE, 1982; HERZOG; LEONARD, 2002; RASSIER et al., 2003).

Em 1952, Abbott e Aubert utilizaram contrações com variação de comprimento e estimulação elétrica. Durante o alongamento ativo do músculo havia o desenvolvimento de um pico de força que diminuía no mesmo segundo, e a força isométrica reestabelecida no comprimento final, após aproximadamente 4 segundos, foi maior do que a força isométrica produzida no mesmo comprimento muscular sem o alongamento (ABBOTT; AUBERT, 1952). Pesquisas semelhantes identificaram que esse aumento da força reestabelecida é dependente da velocidade, com maior pico de força em maiores velocidades de alongamento, além de acontecer apenas em comprimentos finais de sarcômeros acima de 2,3 $\mu$ m; parece também haver um deslocamento da relação força $X$ velocidade para maiores valores de força em uma mesma velocidade (EDMAN; ELZIGA; NOBLE, 1982).

Também na locomoção humana a participação das estruturas elásticas chama atenção. Estudos revelam que em declive, onde se tem uma maior utilização de contrações em alongamento, consequentemente maior conservação de energia elástica, o custo metabólico de transporte é menor. Além disso, parece que o próprio mecanismo da locomoção no plano favorece uma fase inicial de apoio com alongamento muscular - conservação de energia potencial elástica - seguida por uma fase de encurtamento na qual essa energia acumulada é liberada, tornando assim a locomoção mais eficiente (MARGARIA, 1968; CAVAGNA, 1968; 1977; KOMI, 2000).

\section{FADIGA MUSCULAR}

Designa-se por fadiga muscular a incapacidade do músculo esquelético de gerar força muscular ou manter os níveis ao longo do tempo (ASCENSÃO et al., 
2003). A fadiga muscular pode acontecer por alterações da homeostasia no próprio músculo esquelético (origem predominantemente periférica), ou alterações do input neural que chega ao músculo, resultando numa redução progressiva da velocidade e frequência de condução. As manifestações de fadiga têm sido associadas ao declínio da força muscular durante e após exercícios submáximos e máximos, à incapacidade de manter uma contração durante certo tempo, à diminuição da velocidade de contração e ao aumento do tempo de relaxamento musculares. A fadiga está associada à diminuição da força produzida por um abalo, no aumento do tempo de contração e do tempo até o relaxamento (FITTS, 2008).

Segundo Fitts (2008), a fadiga muscular causa diminuição da força, da velocidade de contração e da potência. A diminuição da performance se dá, primeiramente, por desequilíbrios metabólicos, e algumas horas ou dias depois pela instalação de um processo inflamatório relacionado à lesão muscular (CHOI; WIDRICK, 2009).

Alterações nas concentrações de cálcio, fosfato e hidrogênio no interior da fibra muscular, bem como a diminuição de ATP disponível na célula durante a contração podem ser responsáveis pela alteração do mecanismo de pontes cruzadas. O cálcio, por exemplo, deve ser retirado do mioplasma e se desligar da troponina para a liberação das pontes cruzadas, mecanismo que fica prejudicado durante a fadiga (WESTERBLAND; LÄNERGREN; ALLEN, 1997). Tais alterações atuam na inibição do estabelecimento de pontes cruzadas, na diminuição da força por ponte cruzada ou mesmo dificultando a separação da ligação actina-miosina, o que impede a formação de um novo ciclo acoplamento-desacoplamento e diminui a contração muscular. Essa dificuldade em desligar as pontes cruzadas faz com que a resistência ao alongamento se mantenha, contudo a força produzida diminui consideravelmente por não se estabelecerem novas pontes cruzadas.

Segundo Westerbland, Länergren e Allen (1997), a demora no desacoplamento de pontes cruzadas acontece tanto em músculos agonistas quanto em antagonistas. Para diminuir a ação antagonista há diminuição da ativação muscular e, consequentemente, da força, o que prejudica o desempenho.

Em relação à ativação muscular como estímulo inicial para a contração, percebe-se em exercícios submáximos ao longo do tempo diminuição da frequência de disparo dos potenciais de ação (PAs), mesmo sem alteração na força ou no torque produzidos. Esse comportamento se explica pela substituição de fibras musculares do Tipo II por fibras Tipo I. As fibras do tipo II são mais fortes e rápidas e que respondem a maiores frequências de ativação, mas não são fibras resistentes. Já as fibras do Tipo I são lentas e com menor capacidade de produção de força e respondem a menores frequências de ativação, contudo tem capacidade de produzir força submáxima durante períodos mais longos (ENOKA, 1995). 
Nesse sentido, tanto mecanismos de controle central ou de ativação muscular, quanto alterações locais da fibra influenciam a instalação de um processo de fadiga. Além disso, o período de recuperação de atividades extenuantes pode ser longo, evidência que sustenta a possibilidade de mecanismos além da concentração de metabólitos como limitadores da tarefa (CHOI; WIDRICK, 2009). Uma das dificuldades de avaliação e identificação desses processos é a variedade de métodos de investigação. Além disso, tem-se optado pela utilização de contrações isométricas ao longo do tempo, contudo, essa seria uma abordagem distante da realidade, pois em atividades diárias acabamos utilizando ciclos de contração em alongamento-encurtamento. A diferença parece estar, conforme abordado nos capítulos anteriores, na participação dos elementos elásticos no desempenho de uma tarefa. Enquanto que as contrações puramente concêntricas ou isométricas dependem da ativação muscular e da disponibilidade de substrato energético para as pontes cruzadas, o trabalho excêntrico e os ciclos alongamento-encurtamento contam com a energia potencial elástica armazenada nos elementos passivos de produção de força (KOMI, 2000).

Em estudo comparativo entre estímulos de fadiga (contrações concêntricas eletricamente estimuladas) e de dano muscular (estimulação elétrica durante alongamento muscular), Choi e Widrick (2009) encontraram diminuição na potência muscular de fibras isoladas após fadiga, após lesão e após estímulos de fadiga e lesão. Contudo, a diminuição do desempenho foi mais evidente após estímulo de lesão e lesão associada à fadiga. Ou seja, a fadiga local por acúmulo de metabólitos não teve influência tão grande no desempenho. Além disso, o desempenho foi testado ao longo de 30 minutos após a aplicação dos protocolos. Após 5 minutos de recuperação os músculos submetidos apenas a protocolo de fadiga voltaram ao normal, com seu desempenho semelhante ao grupo controle, enquanto que os músculos submetidos a protocolos de lesão, ou lesão e fadiga aliadas, mantiveram o seu desempenho inferior.

Considerando-se ainda a fadiga neuromuscular e dificuldades na transmissão de PAs, essa característica não deve influenciar o desempenho dos elementos elásticos, pois estes atuam sem a necessidade de ativação. Da mesma forma, ao observar a diminuição de substrato energético para a contração, novamente o desempenho dos elementos elásticos não seria prejudicado. Assim, possivelmente o processo de fadiga leve mais tempo para se instalar em ciclos alongamento-encurtamento do que em contrações isométricas (KOMI, 2000).

A fadiga das estruturas elásticas acontece simplesmente por estresse mecânico, o que seria evidenciado no trabalho excêntrico. $O$ treinamento excêntrico, especificamente, causa a diminuição do torque passivo como efeito agudo, mas 
parece favorecer a adaptação com efeito protetor ao longo do tempo, sendo que indivíduos treinados não sofrem com tanta intensidade os efeitos da fadiga causada pelas contrações em alongamento (LAROCHE; CONNOLLY, 2006; REISMAN; ALLEN; PROSKE, 2009). Há diminuição da tensão passiva nas primeiras horas após exercício e aumento da tensão e da rigidez do tecido ao longo dos dias (HOANG; HERBERT; GANDEVIA, 2007).

Essa adaptação crônica está relacionada ao processo inflamatório desencadeado pelo estresse mecânico e pelas microlesões, que estimulam sinalizadores inflamatórios localizados nos elementos passivos (JASPERS et al., 2004). O mecanismo é responsável por, entre outras funções, estimular a síntese de proteínas para reconstrução do tecido, característica responsável pelo efeito protetor da adaptação.

Da mesma forma os exercícios de alongamento tem a capacidade de alterar as propriedades das estruturas elásticas, permitindo maiores ângulos de mobilidade articular. Contudo, os efeitos do alongamento no desempenho ainda geram discussão (GAJDOSIK, 200 I). Podemos afirmar que existe uma rigidez ideal para a conservação e liberação de energia elástica pelos elementos passivos, um ponto intermediário entre rigidez e complacência. Contudo, não se tem certeza ainda de que o alongamento apenas mantenha as estruturas com rigidez ideal ou as deixe ineficientes por aumentar sua complacência em excesso, assim como a fadiga.

\section{FADIGA E COMPONENTES ELÁSTICOS DURANTE A LOCOMOÇÃO}

Estudos realizados em seres humanos e animais propõem que a locomoção se dá através do mecanismo do pêndulo invertido: os membros agem de forma simultânea e oposta (CAVAGNA et al., 1977; GRIFFIN et al., 2004). Durante esse processo o centro de massa se desloca e há trocas constantes de energia. A energia potencial gravitacional e a energia cinética flutuam de forma inversa (CAVAGNA et al., 1977).

No plano o corpo está sujeito a trocas de energia potencial e cinética, no entanto essas trocas acontecem de forma bastante equilibrada, sendo a soma das duas um valor muito próximo de zero (MARGARIA, 1968; CAVAGNA, 1977). Essas variações de energia representam o trabalho mecânico externo. Produzimos trabalho negativo ao longo da aterrissagem e, logo em seguida, trabalho positivo na impulsão, e os dois se equilibram durante o passo (MARGARIA, 1968). Ao descrever as variações de energia como compostas por trabalhos positivos e negativos, Cavagna et al. (1968) relacionam o trabalho positivo com a contração concêntrica - dependente unicamente de energia metabólica - e o trabalho negativo com a contração excêntrica - colaboração das estruturas elásticas. 
Também a corrida é composta por ciclos alongamento-encurtamento, no entanto adota-se um modelo biomecânico massa-mola, sendo a mola representada pelo membro inferior e a massa pelo peso corporal (DELLEAU et al., 1998).

Se aceita, assim, que, durante a aterrissagem, o músculo, bem como as estruturas elásticas, alongam e conservam energia elástica. Essa energia é liberada durante a impulsão, facilitando o encurtamento muscular. A Figura 2 apresenta as fases do passo.

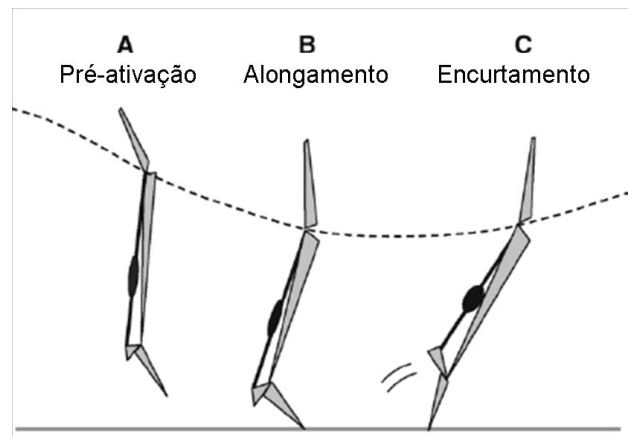

Figura 2. Fases da locomoção em humanos. A) pré- ativação; B) alongamento das estruturas elásticas; C) encurtamento ativo somado à liberação de energia elástica. Adaptado de Komi, 2000.

De maneira detalhada, Lee et al. (2008) afirmam que as pernas dos animais encurtam quando sustentam uma carga - neste caso o peso do corpo - e alongam produzindo força assim que a carga é retirada. Na corrida essa relação inversa reflete o funcionamento de mola composta por todas as estruturas passivas do sistema músculo-esquelético, um mecanismo capaz de conservar e dissipar/transmitir energia. Esse comportamento massa-mola é considerado um dos principais fatores minimizadores do gasto de energia metabólica na locomoção (BOSCO; RUSKO, 1983; LEE et al., 2008). Principalmente na corrida, há maior deformação dos elementos passivos, sem alterar sua rigidez, ocasionando maior conservação de energia elástica quando comparada a caminhada (BOSCO; RUSKO, 1983; DALLEAU et al., 1998).

Quando andamos em inclinações, as relações entre trabalho positivo e trabalho negativo se alteram: o primeiro é maior em aclive e o segundo é maior em declive. Ademais, ao caminhar em declive o trabalho negativo se soma à força da gravidade. Em aclive a força necessária para deslocar o centro de massa e a aceleração da gravidade tem vetores em direções opostas que se subtraem, con- 
sequentemente, a força necessária deve ser maior; já em declive a força necessária para mover o centro de massa e a aceleração da gravidade têm vetores na mesma direção e se somam, diminuindo a força necessária. Assim, a impulsão dependente da força muscular não é mais a única força a atuar para mover o corpo para frente.

A força muscular necessária diminui em até 60\% (MARGARIA, 1968). A aceleração da gravidade, entretanto, exige que o corpo desenvolva mecanismos de desaceleração, gerando conservação de energia elástica nas estruturas passivas, a qual é transmitida na impulsão. Assim, há aumento no trabalho mecânico pela quantidade de energia elástica conservada e liberada, e trabalho metabólico reduzido pela utilização dessa energia no encurtamento muscular. Segundo equações desenvolvidas por Alexander em 1997, em velocidades negativas, ou seja, contração excêntrica, as propriedades do tendão seriam evidenciadas e, consequentemente, o trabalho metabólico seria reduzido sem prejudicar o desempenho.

A Figura 3 reflete a consequência do maior trabalho positivo em aclive e do maior trabalho negativo em declive, nas situações caminhando e correndo. Observa-se maior gasto de energia metabólica em aclive (trabalho positivo) e menor gasto de energia metabólica em declive (trabalho negativo). Segundo Margaria (1968), esse aumento por km em aclive em relação ao plano é de $25 \%$, enquanto que em declive há diminuiçã̃o de $20 \%$ de gasto de energia. Outros estudos encontram ainda maior ativação muscular concomitante ao aumento do trabalho positivo em aclive (DALEY; BIEWENER, 2003). Tais evidências reforçam a utilização da energia elástica das estruturas passivas no desempenho.

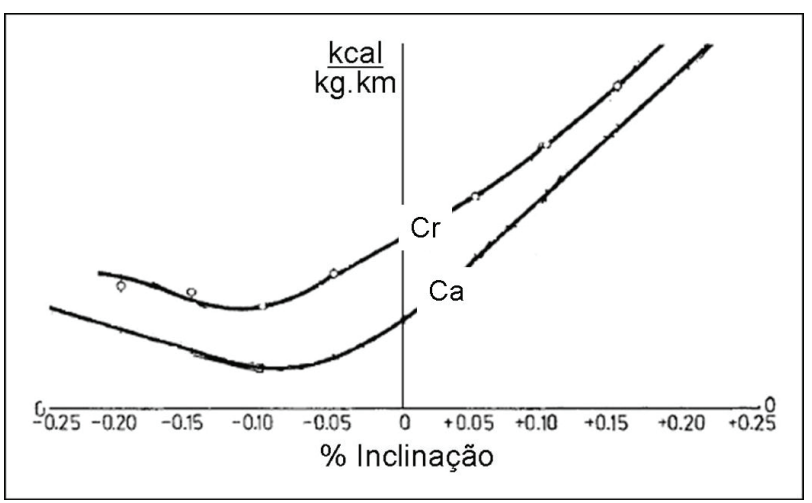

Figura 3. Gasto energético caminhando na velocidade mais econômica (Ca) e correndo $(\mathrm{Cr})$ em relação à inclinação.

Fonte: Adaptado de Margaria, 1968. 
A utilização de energia elástica durante a locomoção, entretanto, faz com que não apenas a fadiga dos componentes contráteis afete o desempenho, mas também a fadiga dos componentes elásticos. De Zee, Bojsen-Moller e Voigt (2000) afirmam que após cargas cíclicas como uma maratona, por exemplo, o tendão muda seu comprimento e parece sofrer alterações em sua complacência associada apenas à reestruturação de suas fibras, ou ainda a lesões no tecido. O tendão se torna menos rígido, o que neste caso indica diminuição da energia elástica conservada e liberada.

Podemos perceber os efeitos da fadiga na locomoção por maior pré-ativação antes do contato do calcanhar com o solo, na diminuição da fase excêntrica e transição imediata entre a fase excêntrica e a fase concêntrica. Esses comportamentos caracterizam a locomoção mais rígida, com menor participação da energia elástica e maior dependência da força produzida por ponte cruzada.

Neste sentido, as provas de maratona são uma ferramenta adequada para o estudo de instalação da fadiga por cargas submáximas em ciclos de alongamento-encurtamento, tanto nos componentes contráteis quanto nos componentes elásticos. A Figura 4 representa as fases do passo e as modificações na força de reação do solo na corrida após a realização de uma maratona, de acordo com Komi (2000).

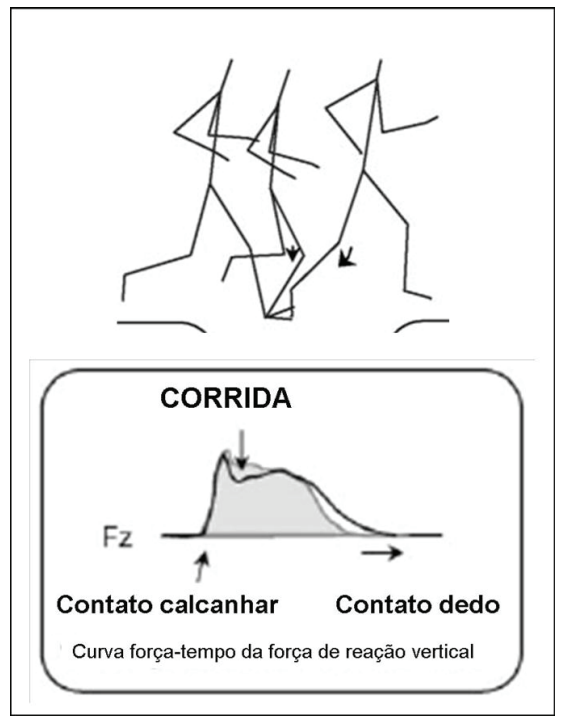

Figura 4. Fases do passo e as alterações na força de reação vertical antes e depois de uma maratona explicar. Linha preta: comportamento da força de reação vertical em um passo normal; área cinza: comportamento da força de reação vertical após uma maratona.

Fonte: Adaptado de Komi (2000). 
Percebe-se a continuidade da força após o toque do calcanhar, sem a definição de pico de aterrissagem e pico de impulsão, bem como a diminuição do tempo de contato com o solo e na força após o impacto. Essas alterações estão relacionadas com a dificuldade em manter os mesmos ângulos de movimento, o que acaba causando diminuição da fase excêntrica e, consequentemente, menor quantidade de energia potencial elástica armazenada e liberada na impulsão. Os mecanismos envolvidos na fadiga por ciclos de alongamento-encurtamento são semelhantes àqueles de contrações puramente excêntricas (KOMI, 2000).

Com uma abordagem diferente, De Zee, Bojsen-Moller e Voigt (2000) estimaram os efeitos de uma maratona com a utilização de tendões de porcos para verificar as propriedades do tecido quando submetido a cargas cíclicas (alongamento-encurtamento). Modificações diferença entre energia conservada e energia liberada decorrentes de alteração no comprimento e na complacência do tendão acontecem nos primeiros 20-25 min de cargas cíclicas e depois se estabilizam. Os resultados indicam diminuição na capacidade de armazenar energia elástica (DE ZEE; BOJSEN-MOLLER; VOIGT, 2000).

Komi (2000) propõe a sequência de mecanismos para a alteração da performance por perda de energia elástica. As alterações nas propriedades mecânicas dos elementos passivos como consequência do esforço, segundo ele, geram a deterioração da função muscular com diminuição da tolerância ao impacto. Isso reduz a energia potencial elástica armazenada nos elementos passivos e, consequentemente, aumenta a necessidade de energia metabólica para um novo encurtamento muscular.

\section{CONCLUSÃO}

Os déficits de desempenho após longos períodos de exercício são visíveis. A diminuição da capacidade de gerar força, da velocidade de contração e da potência são alguns dos efeitos da fadiga. Contudo, os mecanismos internos que limitam o exercício ainda não estão totalmente elucidados. A dificuldade de estabelecer pontes cruzadas pode ser fator chave nesse processo, mas é apenas uma consequência de outros fenômenos metabólicos e neuromotores que se desenvolvem durante o exercício. Além disso, alterações no comportamento dos elementos passivos (elásticos) de produção de força também estão envolvidas no processo.

Durante a locomoção, tarefa que envolve elementos contráteis e elásticos de produção de força, percebe-se claramente a influência dos dois na instauração da fadiga com alterações na ativação muscular e na força, mas também no comportamento do tendão. 
Conclui-se com este estudo que, assim como a força muscular é composta por componentes ativos e passivos de produção de força, a fadiga influencia o desempenho por afetar tanto um quanto o outro.

\section{Elastic Structures and Muscular Fatigue}

ABSTRACT: Muscle weakness can be defined as the inability to keep a certain task over time; neuromuscular and metabolic mechanisms involved in muscle contraction are directly associated with this physical process. This bibliographical study seeks to describe the changes in contractile and elastic elements involved in muscle contraction and its relation to performance in locomotion. The contractile structures are those that develop active force with metabolic energy expenditure - a mechanism of cross-bridges, the elastic ones are those that offer mechanical resistance to stretching at no energy cost - passive force - and keep energy to a new elastic contraction. Therefore muscle weakness is associated with the function of contractile and elastic structures.

KEYWORDS: Contractile elements; elastic elements; muscle weakness; locomotion.

\section{Estructuras elásticas y fatiga muscular}

RESUMEN: La fatiga muscular puede ser definida por la incapacidad de mantener cierta tarea a lo largo del tiempo; los mecanismos neuromusculares y metabólicos involucrados en la contracción muscular están directamente asociados a este fenómeno. Este estudio bibliográfico busca describir los cambios en los elementos contráctiles y elásticos involucrados en la contracción muscular y su relación con el desempeño en la locomoción. Las estructuras contráctiles son aquellas que desarrollan fuerza activa con gasto de energía metabólica mecanismos de puentes cruzados; las elásticas son aquellas que ofrecen resistencia mecánica al estiramiento sin costos energéticos - fuerza pasiva - y conservan energía elástica para una nueva contracción. Por eso la fatiga muscular está asociada a la función de las estructuras contráctiles y elásticas.

PALABRAS CLAVE: Elementos contráctiles; elementos elásticos; fatiga muscular; locomoción.

\section{REFERÊNCIAS}

ABBOTT, B. C.; AUBERT, X. M. The force exerted by active striated muscle during and after change of length. Journal of Physiology, v. I 17, p. 77-86, 1952.

AMENT, W.; VERKERKE, G. J. Exercise and Fatigue. Sports Medicine; v. 39, n. 5, p. 389-422, 2009.

ALEXANDER, R. M. Optimum muscle design for oscillatory movement. Journal of Theory and Biology, v. I84, p. 253-259, 1997. 
ALEXANDER, R. M. Tendon elasticity and muscle function. Comparative Biochemistry and Physiology, v. 133, p. 1001-1011, 2002.

ASCENSÃO, A. et al. Revista Portuguesa de Ciência do Desporto, Porto, v. 3, n. I, p. I08I23, 2003.

BARON, B. et al. Why does exercise terminate at the maximal lactate steady state intensity? British Journal of Sports Medicine, v. 43, n. 4, p. 310 - I, 2007.

BORG, T. K.; CAULFIELD, J. B. Morphology of connective tissue in skeletal muscle. Tissue Cell, v. 12, p. 197-207, 1980.

BOSKO, C.; RUSKO, H. The effect of prolonged skeletal muscle stretch-shortening cycle on recoil of elastic energy and energy expenditure. Acta Physiologica Scandinavica, v. I I 9 , p, $219-224,1983$.

CAVAGNA, G. A.; DUSMAN, B.; MARGARIA, R. Positive work done by a previously stretched muscle. Journal of Applied Physiology, v. 24, n. I, p. 21-32, 1968.

CAVAGNA, G. A.; HEGLUND, N. C.; TAYLOR, C. R. Mechanical work in terrestrial locomotion: two basic mechanisms for minimizing energy expediture. American Journal of Physiology, v. 233, p. 243-261, 1977.

CHOI, S. J.; WIDRICK, J. J. Combined effects of fatigue and eccentric damage on muscle power. Journal of Applied Physiology, v. I07, p. I I 56- I I 64, 2009.

DALEY, M. A.; BIEWENER, A. A. Muscle force-length dynamics during level versus incline locomotion: a comparison of in vivo performance of two guinea fowl ankle extensors. Journal of Experimental Biology, v. 206, p. 294I-2958, 2003.

DALLEAU, G. et al. The spring-mass model and the energy cost of treadmill running. European Journal of Applied Physiology, v. 77, p. 257-263, 1998.

DE ZEE, M.; BOJSEN-MOLLER; VOIGT, M. Dynamic viscoelastic behavior of lower extremity tendons during simulated running. Journal of Applied Physiology, v. 89, p. I352- I 359, 2000.

EDMAN, K. A. P.; ELZINGA, G.; NOBLE, M. I. M. Residual force enhancement after stretch of contracting frog single muscle fibers. Journal of Genetical Physiology, v. 80, p. 769-784, 1982.

ENOKA, R. M. Mechanisms of muscle fatigue: central factors and task dependency. Journal of Electromyogrphy Kinesiology, v. 5, n. 3, p. |4|-149, 1995.

FITTS, R. H. The cross-bridge cycle and skeletal muscle fatigue. Journal of Applied Physiology, v. I04, p. 55I-558, 2008.

GAJDOSIK, R. L. Passive extensibility of skeletal muscle: review of the literature with clinical implications. Clinical Biomechanics, v. 16, p. 87-101, 2001. 
GORDON, A. M.; HUXLEY, A. F.; JULIAN, F. J. The variation in isometric tension with sarcomere length in vertebrate muscle fibres. Journal of Physiology, v. I 84, p. I70- 192, 1966.

GOSSELIN, L. E. et al. Effect of exercise training on passive stiffness in locomotor skeletal muscle: role of extracellular matrix. Journal of Applied Physiology, v. 98, p. I0 I I-10 I6, I 998.

GRANZIER, H. L. M.; LABEIT, S. The giant muscle protein titin is an adjustable molecular spring. Exercise Sports Sciences Reviews, v. 34, n. 2, p. 50-53, 2006.

GRIFFIN, T. M.; MAIN, R. P.; FARLEY, C. T. Biomechanics of quadrupedal walking: how do four-legged animals achieve inverted pendulum-like movements? Journal of Experimental Biology, v. 207, p. 3545-3558, 2004.

HERZOG, W.; TER KEURS, H. E. D. J. Force-length relation of in-vivo human rectus femoris muscles. European Journal of Physiology, v.4II, p. 642-647, 1988.

HERZOG, W. The biomechanics of muscle contraction: optimizing sport performance. Sport Ortho Trauma, v. 25, p. 286-293, 2009.

HERZOG, W.; LEONARD, T. R. Force enhancement following stretching of skeletal muscle: a new mechanism. Journal of Experimental Biology, v. 205, p. 1275- I 283, 2002.

HOANG, P. D.; HERBERT, R. D.; GANDEVIA, S. C. Effects of eccentric exercise on passive mechanical properties of human gastrocnemius in vivo. Medicine and Science in Sports and Exercise, v. 39, n. 5, p. 849-857, 2007.

HOPKINS, G. H. The improbable central governor of maximal endurance performance. Sports and Sciences, v. 13, p. 9-12, 2009.

HUXLEY, A. F; NIEDERGERKE, R. Structural changes in muscle during contraction. Nature, v. 173, p. 97।-973, 1954.

HUXLEY, H.; HANSON, J. Changes in the cross-striations of muscle during contraction and stretch and their structural interpretation. Nature, v. 173, p. 973-976, 1954.

HUXLEY, A. F. Muscle structure and theories of contraction. Progress Biophysical Chemical, n. 7, p. 255-318, 1957.

JASPERS, R. T. et al. Effects of strain on contractile force and number of sarcomeres in series of xenopus leavis single muscle fibres during long-term culture. Journal of Muscle Research Cell Motil, v. 25, p. 285-296, 2004.

JOUMAA, V. et al. Passive force enhancement in single myofibrils. European Journal of Physiology, v. 455, p. 367-37I, 2007.

KOMI, P. V. Stretch-shortening cycle: a powerful model to study normal and fatigued muscle. Journal of Biomechanics, v. 33, p. I197-1206, 2000. 
LABEIT, D. et al. Calcium-dependent molecular spring elements in the giant protein titin. Proceedings of the National Academy of Science, USA, v. I00, p. 13716-13721, 2003.

LAROCHE, D. P.; CONNOLLY, D. A. J. Effects of stretching on passive muscle tension and response to eccentric exercise. American Journal of Sports Medicine, v. 34, n. 6, p. 1000 1007, 2006.

LEE, E-J.; JOUMAA, V.; HERZOG, W. New insights into the passive force enhancement in skeletal muscles. Journal of Biomechanics, v. 40, p. 719-727, 2007.

LEE, D. V. et al. Compliance, actuation, and work characteristics of the goat foreleg and hindleg during level, uphill, and downhill running. Journal of Applied Physiology, v. 104, p. |30-|4|, 2008.

LINKE, W. A. et al. Nature of PEVK-titin elasticity in skeletal muscle. Biophysics, v. 95, p. 8052-8057, 1998.

MACINTOSH, B. R.; MACNAUGHTON, M. B. The length-dependence of muscle active force: considerations for parallel elastic properties. Journal of Applied Physiology, v. 98, p. $1666-1673,2005$.

MARGARIA, R. Positive and negative work performances and their efficiencies in human locomotion. International Zangew Physiologisch einschl Arbeitsphysiol, v. 25, p. 339-35I, 1968.

MARUYAMA, K. et al. Connectin, an elastic protein of muscle: characterization and function. Journal of Biomechanics, v. 82, p. 317-337, 1977.

MINAJEVA, A. et al. Unfolding of titin domains explains the vicoelastic behavior of skeletal myofibrils. Biophyscal Journal, v. 80, p. |442-|45।, 2001.

NATORI, R. The role of myobibrils, sarcoplasm and sarcolemma. Jikeikai Medicine Journal, v. I, p. 18-28, 1954.

PINNIGER, G. J.; RANATUNGA, K. W.; OFFER, G. W. Crossbridge and non-crossbridge contributions to tension in lengthening rat muscle: force-induced reversal of the power stroke. Journal of Physiology, v. 573, n. 3, p. 627-43, 2006.

PURSLOW, P. P. Strain-induced reorientation of na intramuscular connective tissue network: implications for passive muscle elasticity. Journal of Biomechanics, v. 22, p. 22 I-312, 1989.

RASSIER, D. E. et al. Stretch-induced, steady-state force enhancement in single skeletal muscle fibres exceed the isometric force at optimum fiber length. Journal of Biomechanics, v. 36, p. 1309-1316, 2003.

REISMAN, S.; ALLEN, T. J.; PROSKE, U. Changes in passive tension after stretch of unexercised and eccentrically exercised human plantar flexor muscles. Experimental and Brain Research, v. 193, p. 545-554, 2009. 
SANDERCOCK, T. G. Nonlinear summation of force in cat soleus muscle results primarily from stretch of the common-elastic elements. Journal of Applied Physiology, v. 82, p. 2206$22 \mid 4,2000$.

SCHLEIP, R. et al. Passive muscle stiffness may be influenced by active contractility of intramuscular connective tissue. Med Hypoth, v. 66, p. 66-7I, 2006.

TAYLOR, J. L.; GANDEVIA, S. C. A comparison of central aspects of fatigue in submaximal and maximal voluntary contractions. Journal of Applied Physiology, v. 104, p. 542-550, 2008.

TSKHOVREBOVA, L.; TRINICK, J. Role of titin in vertebrate striated muscle. Phil Transactions Royal Society of London B, v. 25, p. 199-206, 2003.

WATERMAN-STORER, C. M. The cytoskeleton of skeletal muscle: is it affected by exercise? Medicine and Science in Sports and Exercise, v. 23, p. 1240-1249, 1991.

WESTERBLAND, H.; LÄNNERGREN, J.; ALLEN, D. G. Slowed relaxation in fatigued skeletal muscle fibers of xenopus and mouse. Journal of Genetical Physiology, v. 109, p. 385-399, 1997.

WILLIAMS, P. E.; GOLSPINK, G. Connective tissue changes in immobilized muscle. Journal of Anatomy, London, v. I38, p. 342-50, 1984.

WOITTIEZ, R. D. et al. A three-dimensional muscle model: a quantified relation between form and function of skeletal muscles. Journal of Morphology, v. I I3, p. I82-195, 1984.

Recebido em: 3 maio 2010 Aprovado em: 4 jan. 201 I

Endereço para correspondência: Gláucia Andreza Kronbauer Instituto Federal do Paraná, IFPR Rua Pedro Koppe, 100 Vila Matilde Irati, PR CEP: 84500-000 